\title{
Itinerário terapêutico de crianças com microcefalia pelo vírus Zika
}

\author{
Therapeutic itinerary of children with microcephaly due to the \\ Zika virus
}

Daniela Santos Bosaipo (https://orcid.org/0000-0003-4533-4429) ${ }^{1}$

Zeni Carvalho Lamy (https://orcid.org/0000-0002-9332-0542) ${ }^{2}$

Poliana Soares de Oliveira (https://orcid.org/ 0000-0003-3596-0194) ${ }^{3}$

Clarice Maria Ribeiro de Paula Gomes (https://orcid.org/0000-0001-7707-9050) ${ }^{4}$

Milena Ribeiro Mendes de Assis (https://orcid.org/0000-0002-7726-6638) ${ }^{4}$

Marizélia Rodrigues Costa Ribeiro (https://orcid.org/0000-0003-4289-4527) ${ }^{5}$

Maria Teresa Seabra Soares de Britto e Alves (https://orcid.org/0000-0002-4806-7752) ${ }^{5}$

${ }^{1}$ Faculdade de Medicina, Universidade Federal do

Maranhão. Praça Gonçalves

Dias 21, Centro. 65020-240

São Luís MA Brasil.

danielabosaipo@gmail.com

${ }^{2}$ Departamento de Saúde

Pública, Universidade

Federal do Maranhão. São

Luís MA Brasil.

${ }^{3}$ Universidade Federal do

Maranhão. São Luís MA

Brasil.

${ }^{4}$ Núcleo de Estudos Sobre

Saúde e Subjetividade,

Universidade Federal do

Maranhão. São Luís MA

Brasil.

${ }^{5}$ Centro de Ciências da

Saúde, Universidade Federal

do Maranhão. São Luís MA

Brasil.

\begin{abstract}
In 2015, there was an epidemic of microcephaly in Brazil that was associated with infection by the Zika virus. The condition of these children obliged the parents to embark on a quest in search of treatment. The scope of this study was to establish the therapeutic itinerary pursued in healthcare sectors by parents and/or caregivers of children with microcephaly due to the Zika virus. It involved qualitative research, conducted at a Center of Reference on Neurodevelopment between April 2017 and February 2018, with parents and/or caregivers of children with microcephaly caused by the Zika virus. The sample complied with the criteria of saturation. Twenty semi-structured interviews were conducted, recorded, and transcribed, and content analysis was applied. The results revealed disorientation and uncertainties in the search for care in the health sector. The most sought-after sector was the professional sector, followed by the informal sector. The information conveyed in the media and social networks, which constitute part of the informal sector, helped to clarify the significance of microcephaly and the Zika virus and assisted in the search for treatment. Care in the healthcare network was marked by difficulties and, faced with a new and emergency situation, the route between diagnosis and treatment was arduous.
\end{abstract}

Key words Zika virus, Microcephaly, Therapeutic itinerary
Resumo Em 2015, no Brasil, houve uma epidemia de microcefalia que foi associada à infeç̧ão pelo vírus Zika. A condição destas crianças impulsionou os pais a percorrerem um caminho em busca por tratamento. O objetivo deste estudo foi conhecer o itinerário terapêutico percorrido por pais elou cuidadores de crianças com microcefalia pelo vírus Zika nos setores de atenção à saúde. Pesquisa de abordagem qualitativa, realizada em um Centro de Referência em Neurodesenvolvimento, no periodo de abril de 2017 a fevereiro de 2018, com pais e/ou cuidadores de crianças com microcefalia pelo vírus Zika. A amostra obedeceu aos critérios de saturação de sentidos. Foram feitas 20 entrevistas semiestruturadas, gravadas e transcritas. Realizou-se análise de conteúdo, na modalidade temática. Os resultados demostraram desorientação e incertezas na busca pelo cuidado nos setores de saúde. O setor mais procurado foi o profissional, seguido pelo informal e popular. As informações veiculadas na mídia e redes sociais, que fazem parte do setor informal, contribuíram para esclarecer o significado da microcefalia e vírus Zika e auxiliou na busca por tratamento. $O$ cuidado na rede de Atenção à Saúde foi marcado pela peregrinação. Diante de uma situação nova e emergencial, o caminho percorrido, entre o diagnóstico e o tratamento, foi árduo.

Palavras-chave Zika vírus, Microcefalia, Itinerário terapêutico 


\section{Introdução}

A microcefalia é uma malformação congênita na qual o cérebro não se desenvolve de forma apropriada $^{1}$. Caracteriza-se, segundo a Organização Mundial de Saúde (OMS), por um perímetro cefálico inferior a 2 desvios-padrão, ou seja, abaixo da média para idade gestacional e sexo ${ }^{2}$.

Em 2015, após um aumento súbito do número de casos, o Ministério da Saúde do Brasil associou esta malformação à transmissão vertical do vírus Zika ${ }^{3,4}$. Diante da epidemia, em 2016, foi decretado Estado de Emergência Internacional em Saúde Pública pela OMS e, em abril do mesmo ano, pesquisas confirmaram que a infecção pelo vírus Zika poderia levar a outras morbidades além da microcefalia, como epilepsia, deficiências auditivas e visuais, sendo denominada de Síndrome Congênita pelo Vírus Zika (SCZ) ${ }^{5,6}$.

As crianças com microcefalia apresentam atraso no desenvolvimento neuropsicomotor com acometimento cognitivo em cerca de $90 \%$ dos casos, podendo também comprometer as funções sensitivas ${ }^{1}$. As características clínicas da microcefalia, decorrentes dos déficits no desenvolvimento da criança, aumentam as suas demandas por cuidados ${ }^{7,8}$.

Nesse sentido, a família se vê frente ao desafio de ajustar seus planos e expectativas, além da necessidade de enfrentar uma árdua busca por assistência. Esta situação é ainda mais grave para a mulher, tendo em vista que, na maioria dos casos, é quem fica diretamente envolvida com os cuidados da criança'.

Dois conceitos são muito importantes para que se compreenda os caminhos percorridos em busca de cuidados. O primeiro é trajetória assistencial, utilizado quando as pessoas buscam a solução de alguma questão relacionada à saúde envolvendo tão somente as instituições de saúde, o diagnóstico e tratamento de doenças, os profissionais, como médicos e suas prescrições ${ }^{10}$. O segundo é itinerário terapêutico, termo usado para designar o caminho percorrido pelos usuários e suas famílias nos diferentes setores em busca de tratamento para a doença ou aflição ${ }^{11}$, a saber: setor profissional, que envolve profissões legalmente reconhecidas e sancionadas; setor popular, que envolve os sistemas de cura não oficiais, operacionalizados por curandeiros ou outras pessoas especialistas na ação sagrada ou em conhecimentos seculares e o setor informal, que compreende o domínio leigo representado por cuidados casei$\operatorname{ros}^{12,13,14}$.

O tipo de busca pelos cuidados da criança depende de questões como fatores culturais, socio- econômicos e escolaridade. Para Alves e Sousa, no curso dessas ações, evidentemente, fazem-se presentes interesses, emoções e atitudes circunstanciais que envolvem um conjunto de planos, estratégias e projetos voltados para um objeto preconcebido: o tratamento da aflição ${ }^{14}$.

Destaca, também, que o itinerário terapêutico não é necessariamente produto de um plano esquematizado, pré-determinado, mas sim, que se organiza como uma cadeia de eventos sucessivos que se articulam entre $\mathrm{si}^{14}$.

A importância dos estudos sobre itinerários terapêuticos está em dar luz às experiências vividas pelos indivíduos ao realizarem os seus percursos em busca de atenção e tratamento, valorizando a multiplicidade de caminhos e escolhas presentes nesse processo ${ }^{14} \mathrm{e}$ identificando as dificuldades enfrentadas pelas famílias no sentido de oferecer subsídios para planejamento, organização e avaliação de serviços assistenciais de saúde, criação de fluxos de cuidado e ainda fomentar a qualificação da atenção à saúde da criança ${ }^{15,16}$.

O objetivo deste estudo foi conhecer o itinerário terapêutico percorrido por pais e/ou cuidadores de crianças com microcefalia pelo vírus Zika nos setores de atenção à saúde.

\section{Metodologia}

Neste trabalho foi utilizada a abordagem qualitativa do tipo exploratória. A pesquisa foi realizada na cidade de São Luís, capital do estado do Maranhão, no período de abril de 2017 a fevereiro de 2018.

A microcefalia já era endêmica em São Luís, antes da epidemia de Zika e, em 2015, logo no início da epidemia, foram descritas 48 crianças com microcefalia e/ou alterações congênitas do Sistema Nervoso Central, atendidas no Centro de Referência Estadual em Neurodesenvolvimento, Assistência e Reabilitação de Crianças (Ninar) ${ }^{17}$, local de realização da pesquisa.

O Ninar já oferecia serviços de assistência e reabilitação a crianças com necessidades especiais e durante a epidemia pelo vírus Zika foi ampliado e inaugurada uma casa de apoio (Ninar II) com equipe multiprofissional em que, além de atendimento especializado, é ofertada hospedagem para as famílias do interior, oficinas, cursos e palestras aos familiares e capacitação de profissionais de outras unidades que acompanham as crianças em tratamento.

Os participantes do estudo foram pais e/ou cuidadores de crianças com diagnóstico de microcefalia presumível por Zika, que faziam se- 
guimento no Ninar. Para a seleção da amostra, o primeiro passo foi identificar todas as crianças matriculadas no momento do estudo (total de 146), e construir um quadro com características dos pais e das crianças. Esse quadro nos permitiu conhecer o universo dos participantes, para escolher de forma intencional, com a ajuda de uma informante-chave (profissional que conhecia bem as famílias), a amostra da pesquisa, buscando contemplar as diferentes histórias, considerando idade, escolaridade, estrutura familiar, renda, procedência e momento do diagnóstico.

A definição do número de entrevistas atendeu aos critérios de saturação, que ocorre quando o pesquisador suspende as entrevistas considerando que conseguiu compreender a lógica interna do grupo $^{18}$.

A técnica principal utilizada para a coleta de dados foi a entrevista em duas modalidades: estruturada e semiestruturada. Para cada técnica foi construído um instrumento: questionário estruturado com dados quantitativos e roteiro de entrevista semiestruturada.

O questionário estruturado continha dados de identificação da criança, características socioeconômicas e demográficas; antecedentes maternos e paternos; dados relacionados à gestação, parto e nascimento; sintomas e diagnóstico de problemas após o nascimento; fenótipo e outras alterações no exame físico. Esses dados foram inicialmente coletados do prontuário e complementados na entrevista com os pais.

$\mathrm{O}$ roteiro de entrevista semiestruturada destacava as questões relacionadas à gravidez, ao parto e nascimento, às informações de como recebeu o diagnóstico da microcefalia e de como buscou ajuda e tratamento.

O contato inicial aconteceu na sala de espera do ambulatório ou durante o intervalo das atividades, na casa de apoio. Eram explicados os objetivos da pesquisa e realizado o convite para participação. O local, data e horário eram definidos de acordo com o interesse dos participantes. A entrevista era gravada e posteriormente transcrita.

Sobre os dados, foi utilizada a técnica de análise de conteúdo, na modalidade temática. Os passos utilizados foram a pré-análise; categorização do material, classificando os dados a partir das categorias analíticas e buscando os núcleos de sentido - unidades de compreensão do texto. Em seguida, foram procuradas palavras significativas para fazer a ordenação das categorias empíricas. $\mathrm{Na}$ análise final, foram relacionadas as categorias empíricas com a literatura ${ }^{19}$.
A pesquisa foi autorizada pela Secretaria Estadual de Saúde e aprovada pelo Comitê de Ética em Pesquisa com seres humanos do Hospital Universitário da Universidade Federal do Maranhão (HUUFMA), obedecendo à Resolução 466/12, do Conselho Nacional de Saúde (CNS). Os nomes dos participantes foram substituídos por nomes iniciados com a letra M para as mães, $\mathrm{P}$ para os pais e B para a bisavó.

\section{Resultados e discussão}

Realizaram-se 20 entrevistas: três com pai e mãe juntos, 16 com mães e uma com a bisavó que era a cuidadora da criança.

As mães, principais cuidadoras das crianças, tinham idade entre 15 e 42 anos, maioria casada (9), com ensino médio completo (7), tinham grande variação quanto ao número de filhos (1 a 9) e 13 relataram que não havia planejado a gestação deste filho.

Quanto aos três pais entrevistados, a idade variou entre 26 e 29 anos, sendo dois casados e um em união consensual; dois com ensino médio completo e um com fundamental completo, apenas um deles estava desempregado, os outros eram empregados formais.

A renda das famílias variou de 1 a 3,5 salários mínimos, sendo que uma família declarou renda mensal de 12 salários mínimos. Em relação aos municípios de residência, 12 entrevistados moravam no interior do estado.

As crianças, no momento da coleta de dados, tinham idade entre 11 meses e 2 anos e 2 meses, a maioria do sexo feminino. A maior parte nasceu no município de São Luís, em maternidades da rede pública. Em relação ao momento do diagnóstico de microcefalia, em seis casos aconteceu durante a gestação, um durante o trabalho de parto, quatro no momento do nascimento e nove após o nascimento.

As principais características fenotípicas encontradas foram desproporção crânio-facial, depressão biparietal, occipto proeminente e excesso de pele nucal. As comorbidades mais associadas à microcefalia foram epilepsia e visão subnormal.

A construção do itinerário terapêutico percorrido por pais e/ou cuidadores entrevistados se deu a partir do momento que receberam a suspeita e/ou confirmação do diagnóstico de microcefalia. A partir deste momento, procurou-se compreender os caminhos percorridos na busca por cuidados a partir dos setores informal, popular e profissional. 


\section{Desorientação e incertezas: a busca pelo cuidado nos setores de saúde}

A comunicação de um diagnóstico que compromete o desenvolvimento infantil, em um momento de uma epidemia nova no país, já demonstra o início das dificuldades que foram encontradas nos itinerários terapêuticos.

A falta de preparo após a comunicação do diagnóstico no sentido de orientar a família em relação aos passos a seguir, por parte dos profissionais, somado à ausência de um fluxo de cuidado foi a marca do início da busca pelo cuidado, a exemplo das falas a seguir:

Primeiro, foi no posto lá [de Itapecuru], aí eles não detectaram [a microcefalia]. Pedro, 29 anos.

Ele [o pediatra] não sabia o que era que ele tinha. Maria, 21 anos.

Eu não sabia nem por onde começar [após o diagnóstico]. Moana, 30 anos.

Como é novo pra gente, é novo pra toda a equipe também. Mônica, 21 anos.

No contexto do surto de Zika, suas graves repercussões e pelo próprio caráter de novidade da SCZ, esse despreparo foi agravado pela falta de conhecimento dos profissionais sobre como conduzir o caso e orientar as famílias.

A equipe de saúde tem um papel fundamental na orientação, esclarecimento de dúvidas e apoio aos anseios da família, tanto sobre as condições das crianças, quanto aos cuidados necessários ${ }^{1,7}$.

A falta de profissionais habilitados para este propósito trazem consigo diversos aspectos que podem restringir o andamento do itinerário terapêutico, contribuindo para que cuidadores e crianças embarquem em trajetórias desconhecidas na busca por mais explicações ${ }^{1,7,15}$.

Os percursos percorridos pelas crianças e suas famílias com o objetivo de resolver as suas necessidades perpassaram os diversos setores de cuidado à saúde, com predomínio pelo setor profissional, como era esperado, considerando que o ponto de partida para o encontro com as crianças foi o sistema de saúde.

Para Kleinman, cada setor tem seu modelo explicativo ${ }^{12}$. Segundo este autor, modelos explicativos são as concepções sobre a enfermidade e as formas de tratamento e vão definir qual setor do Sistema de Atenção à Saúde será acionado no processo de cuidado ${ }^{12,16}$.

Gerhardt destaca que, nos episódios graves, as famílias costumam recorrer imediatamente ao atendimento médico na rede pública através de ambulatórios, serviços de urgência e emergência, hospitais, consultórios médicos e clínicas ${ }^{20}$.
Além disso, o que a família define como episódio grave é influenciado pelas vivências, experiências e informações acumuladas, aliando conhecimentos biomédicos e populares de saúde ${ }^{20}$.

Com isso, é possível que esta seja uma explicação para o resultado deste estudo. A epidemia de Zika, que aconteceu no país em 2015 e 2016, teve grande visibilidade e veiculação intensa de notícias através da mídia, internet e redes sociais. Muitas informações, às vezes controversas, sobre a necessidade e os caminhos de busca para atendimento médico, foram disponibilizadas ${ }^{16}$. Tal fato pode ter interferido diretamente pela escolha do setor profissional de cuidado.

O segundo setor mais procurado pelos entrevistados foi o setor informal (12 famílias). Para Gerhardt, uma das explicações é que para os problemas classificados como leves, o médico raramente é procurado diante dos primeiros sintomas ${ }^{20}$.

As formas de uso do setor informal foram buscar orientações na própria comunidade, na internet e participar de grupos de autoajuda.

Muitas famílias chegaram ao centro de referência (Ninar) para o tratamento das crianças com microcefalia por indicação de outras pessoas, especialmente aquelas que estavam passando por situação semelhante.

Eu cheguei no centro de referência através de uma colega. Marina, 18 anos.

Me informei com uma outra mãe [sobre o centro de referência]. Mel, 20 anos.

Nesse sentido, o setor informal tomou grande dimensão na construção dos itinerários, influenciando diretamente na escolha por onde buscar tratamento.

Em geral, essa busca é realizada de acordo com a facilidade de acesso ${ }^{21}$. Por isso o conselho/ indicação de um local no qual alguém que passava por situação semelhante conseguiu atendimento foi muito valorizado.

Além das indicações em relação aos locais de tratamento, as famílias também participaram ativamente do processo de reabilitação das crianças e, com isso, influenciaram diretamente nos cuidados oferecidos, especialmente no que se refere à fisioterapia.

Quem me ensinou a mexer [nos kits de fisioterapia que recebeu] foi a menina, uma outra mãe. Bianca, 73 anos.

Os próprios manuais do Ministério da Saúde destacam que a família tem papel fundamental no tratamento da criança ${ }^{1,2,22}$. Os protocolos recomendam que os pais devem ser orientados sobre a realização de estimulação em casa ${ }^{22}$. Ao se 
apropriarem desse conhecimento, as mães trocaram informações entre si, como forma de auxílio e muitas aprenderam fora do setor profissional.

Os participantes da pesquisa deram muita importância às informações veiculadas na mídia e nas redes sociais, principalmente através de Grupos de whatsApp, tanto no sentido de esclarecer o significado da Síndrome Congênita pelo Vírus Zika, como também como meio de encontrar formas de tratamento e rede de apoio, como apresentados nas falas de Maria, Moana e Mel:

Eu entrei num grupo de mães só de crianças com microcefalia que é o Macro Amor/Amor Incondicional. Maria, 21 anos.

Depois que eu vim pra cá [São Luís], que eu entrei num grupo de mães só de crianças com microcefalia, que é o Macro Amor, que a gente foi conversando ai que eu fui entendendo realmente o que era microcefalia. Moana, 30 anos.

Fui na internet e vi que ela precisava de fisioterapia e terapia ocupacional. Mel, 20 anos.

A internet e as redes sociais, em um contexto mais atual, são formas de trocar experiências sobre os cuidados com as questões de saúde. Grupos de whatsApp foram acionados nas articulações entre mães de crianças com microcefalia ${ }^{23}$. A importância dessas associações é apontada pela construção de um espaço de produção de práticas, que são como uma ciência doméstica do cuidado que se move paralela à ciência oficial da medicina ${ }^{24}$.

Por conseguinte, sendo a microcefalia associada ao vírus Zika, uma condição grave, cujas informações foram muito difundidas nos diversos meios de comunicação, é possível que tal fato justifique que o setor popular tenha sido buscado somente por duas das mães entrevistadas, como podemos observar nas falas de Mary e Mel:

Todo dia eu levava ela na rezadeira pra tirar os quebrante. [...] Eles [rezadeiras] ensinaram vários remédios, caseiro. Mary, 20 anos.

[Pastoras] foram num monte orar pela saúde. Mel, 20 anos.

As pessoas podem buscar as religiões populares como um importante recurso de cura, para resolver suas demandas. Embora a religiosidade faça parte do universo simbólico e social dos sujeitos, influenciando diretamente nas ações individuais e pode promover bem-estar e induzir atitudes de maior zelo e cuidado para manutenção da saúde ${ }^{25}$, para Ferreira e Espírito Santo isso pode ocorrer, especialmente, em populações de baixa renda quando encontram alguma dificuldade de acesso aos serviços oficiais de saúde ${ }^{21}$.

Portanto, ao constatar que houve uma pluralidade de setores e recursos acionados pelas fa- mílias na busca por tratamento, pode-se perceber que estes funcionaram através de uma lógica de complementaridade, com o objetivo de conseguir atender as demandas de forma mais rápida e eficiente.

\section{Trajetórias assistenciais: o cuidado na rede de atenção à saúde}

Nesta categoria, é discutida a maneira como este grupo acessou o sistema de saúde (setor profissional), onde e como foram atendidos, destacando a trajetória assistencial percorrida.

Os resultados demonstraram que, após o diagnóstico, os encaminhamentos para os serviços de saúde especializados ocorriam de forma desordenada e sem articulação. Muitos locais foram apontados como porta de entrada no sistema para o atendimento a essas famílias, como podemos ver nas seguintes falas:

O Centro de Reabilitação foi o primeiro lugar. Marina, 18 anos.

Deu entrada no Hospital de Emergências. Pedro, 29 anos.

Começamos no Hospital Pediátrico de Referência. Paulo, 26 anos.

As explicações para isso são multifatoriais e passam pela falta de organização dos serviços de saúde, fragilidade e fragmentação da rede assistencial. Destaca-se a falta de conhecimento dos profissionais em termos de diagnóstico e tratamento das crianças que nasceram com SCZ, especialmente no início da epidemia pelo fato de se tratar de uma nova doença, sobre a qual não se conheciam as necessidades terapêuticas e não havia um fluxo para o atendimento dessas crianças ${ }^{5}$.

Nesse contexto da incerteza, um grande desafio foi a transição de uma situação de emergência para o planejamento de longo prazo. $\mathrm{O}$ Brasil, em particular, expandiu sua cobertura de exames diagnósticos mais complexos e centros de reabilitação ${ }^{6}$. No entanto, tem sido difícil garantir que as instituições consigam implementar uma cobertura de atendimento para todas as crianças com SCZ ${ }^{6}$.

A partir disso, foi identificado que morar no interior do estado mostrou-se como um fator não facilitador para acessar o sistema de saúde, como observamos nas falas de Moana e Marcela:

A gente vem [pra São Luís] porque é o jeito. [...] Ai eles pegaram e marcaram e me jogaram pra cá pra São Luís. Moana, 30 anos.

$\mathrm{Na}$ minha cidade não tem nada [profissionais especializados]. Marcela, 35 anos. 
A falta de serviços especializados em algumas cidades, por vezes, obriga as famílias a mudarem ou se deslocarem para localidades onde são oferecidos serviços capazes de atender as necessidades das crianças ${ }^{15}$.

Para esses casos, em especial, quando o cuidador recebeu ajuda durante a busca pelo tratamento de seu filho, seja informal ou formal, as dificuldades para acessar o sistema de saúde foram atenuadas.

Aí... depois eu conheci a Helena. Helena é uma moça que trabalha lá na Secretaria de Codó, na vigilância em saúde. Ela chegou... aí facilitou muita coisa em termo da fisioterapia. Ela me ajuda! Se eu precisar de alguma consulta, basta ligar pra ela e ela consegue pra mim. Moana, 30 anos.

A trajetória percorrida por mães em busca de cuidado e resolutividade das demandas de saúde dos seus filhos é permeada por dificuldades que funcionam como barreiras ao acesso, que as obrigam a fazer caminhos repetidos por diversas instituições, sem sucesso ${ }^{8,15}$. Nesse sentido, as redes de apoio social (informais e formais), minimizam o sofrimento e o desgaste enfrentado pela família ${ }^{15}$.

Ainda foi observado uma postura ativa de algumas mães em buscar o setor profissional, ao perceber que o filho não estava se desenvolvendo conforme o esperado, como evidenciado nas seguintes falas:

Eu consegui pra ela, eu sozinha andando atrás. Maísa, 42 anos.

Ele já tava com seus sete meses, quando eu vi que o meu filho não evoluía. Mila, 20 anos.

Eu não posso ficar só esperando sentada.. Marina, 18 anos.

$\mathrm{Na}$ literatura é possível encontrar relatos de mães que revelam angústia e inquietação diante da demora de respostas para a condição de seus filhos, que muitas vezes levam um tempo muito longo para serem obtidas ${ }^{15}$. Em contrapartida, foi identificado que ter tido o filho em uma maternidade específica da capital do estado mostrou-se um fator facilitador no acesso ao sistema de saúde, principalmente no que se refere à reabilitação, a exemplo das falas:

O diagnóstico foi lá na Maternidade. Já me encaminharam pras fisioterapias. Ela começou a fazer fisioterapia com 3 meses. Então, assim que descobriu o que ela tinha, eles mesmo já me encaminharam, não precisou eu ir atrás, eles mesmo já encaminharam pra fisioterapia e fonoaudióloga e terapeuta. Mônica, 21 anos.

Esta Maternidade referida é de alta complexidade e, em meio à epidemia do vírus Zika, foi o local para onde mulheres com suspeita do diagnóstico de microcefalia foram referenciadas e receberam encaminhamento para o Centro de Reabilitação (CER), serviço de gestão estadual parte de rede de cuidados, que oferece tratamento para pessoas com necessidades de reabilitação física, intelectual e auditiva.

Mesmo após superar os diversos impasses para acessar o sistema de saúde, a escassez de serviços especializados com equipe multiprofissional, associado a encaminhamentos equivocados, levaram à peregrinação e longas filas de espera para $o$ atendimento das crianças. Tantos desafios e obstáculos fizeram surgir nos pais e/ou cuidadores a concepção que enfrentar esta situação seria como uma "luta".

Ela [esposa] lutando de hospital em hospital. [...] E aí começou aquela luta. Paulo, 26 anos.

A gente tá na luta, ela tá com 1 ano e 3 meses, a gente fazendo o tratamento dela. Melissa, 18 anos.

Foi complicado... porque onde a gente foi e os profissionais ficavam jogando de um lado para o outro. Pedro, 29 anos.

Devido a essa situação, muitas crianças não foram atendidas de forma precoce, principalmente no que se refere à reabilitação. No entanto, ao iniciar o tratamento sua avaliação era positiva.

O CER é um lugar onde você tinha tudo pro seu filho, todo o tratamento, que eram as fisio, as fono, as TO. Marisa, 32 anos.

Crianças com microcefalia podem apresentar prejuízos do desenvolvimento neuropsicomotor e necessitam de estimulação precoce ${ }^{1,2,24}$. Após o diagnóstico, e com a criança clinicamente estável, o processo de intervenção precoce objetiva tratar as deficiências primárias, minimizar as secundárias e prevenir deformidades, estimulando a criança a ampliar suas competências ${ }^{7,26}$. É esperado que serviços e profissionais ajudem na busca por soluções para as demandas em saúde com o objetivo de facilitar as trajetórias dos usuários ${ }^{27,28}$.

Além disso, os familiares possuem papel fundamental no tratamento de uma criança com microcefalia, especialmente nas conquistas que esta terá durante a sua vida ${ }^{29}$. Por isso, é imprescindível acolher, orientar e estimular os pais durante o processo de reabilitação do filho ${ }^{28}$.

Em meio a demanda de cuidados que as crianças com SCZ necessitavam, em 2016, o Centro de Referência em Neurodesenvolvimento, Assistência e Reabilitação de Crianças foi ampliado e reinaugurado, para o acompanhamento dessas crianças, fato que foi avaliado positivamente pelos pais e/ou cuidadores. Posteriormente, em 2017, foi criada uma Casa de Apoio, ampliando 
ainda mais o acolhimento e atendimento. Foi a partir da criação deste Centro que a maioria dessas crianças tiveram acesso ao acompanhamento médico especializado, além de tratamentos de reabilitação, a exemplo das falas a seguir:

[Faz acompanhamento] aqui no Centro de Referência.Paulo, 26 anos.

Com a Doutora, ela veio ser acompanhada, depois aqui do Centro de Referência. Moana, 30 anos.

Uma das melhores coisas que teve foi essa casa aqui [Casa de Apoio]. Michele, 19 anos.

Este centro conta com diversos profissionais de saúde da rede estadual que ofertam tratamentos especializados às crianças com problemas de neurodesenvolvimento, em especial a microcefalia. O corpo clínico do centro é formado por pediatras, neuropediatras, oftalmologistas e geneticistas, além de equipe multiprofissional composta por fisioterapeutas, enfermeiros, fonoaudiólogos, assistentes sociais, psicopedagogos e terapeutas ocupacionais ${ }^{28}$.

Desde 2015, já existia na legislação brasileira uma lei com o objetivo de assegurar e promover, em condições de igualdade, os direitos e as liberdades fundamentais da pessoa com deficiência, visando à sua inclusão social e cidadania, a Lei Brasileira de Inclusão da Pessoa com Deficiência, $n^{\circ}$ 13.146 (Estatuto da Pessoa com Deficiência) ${ }^{30}$.

Com isso, cabe ao Estado, à sociedade e à família garantir para a pessoa com deficiência, a efetivação dos direitos referentes à vida, à saúde, à educação, à previdência social e à reabilitação, entre outros, de modo a garantir seu bem-estar pessoal, social e econômico ${ }^{30}$.

Com a abertura do Centro de Referência, os atendimentos que já eram prestados pelo governo às crianças com microcefalia de forma fragmentada e não sistematizada, foram integrados em um único espaço, para maior facilidade de acesso e comodidade às crianças e suas famílias, o que promoveu uma maior integralidade do cuidado.

A rotina exaustiva foi relatada pela maioria dos cuidadores, situação que era agravada para aqueles que moram no interior do estado.

Alguns pais, por essas dificuldades, se viram obrigados a escolher apenas um local para realizar o acompanhando do filho, que geralmente escolhiam o Centro de Referência, como evidenciado nas seguintes falas:

Tinha que ir com ele todo dia nas consultas, de manhã e de tarde, a gente chegava em casa de noite cansada. Mariana, 22 anos.

Eu achava muito longe [o CER]. Mirian, 39 anos.
Eu ficava imaginando a gente viajando do interior pra cá, eu só vivia chorando. Melissa, 18 anos.

Era muito difícil viajar com ela. Pedro, 29 anos.

A demanda por cuidados que uma criança com um quadro crônico e grave, como a microcefalia, altera o funcionamento familiar, repercutindo de forma direta na qualidade de vida ${ }^{26}$.

$\mathrm{O}$ acolhimento, apoio e suporte socioemocional é importante para ajudar as famílias a criar estratégias para lidar com as dificuldades de manejo da vida diária. Desse modo, é necessário além do acompanhamento da criança, atenção aos grupos de pais, já que estes têm papel fundamental no tratamento das crianças, auxiliando a promover saúde mental nessas famílias ${ }^{26}$.

A maioria das mães avaliou positivamente as equipes de saúde que estavam cuidando de seus filhos e os locais onde eram atendidos, especialmente no centro de referência, como observamos nas falas de Mônica, Mel e Marisa:

Eles [A equipe] estão sempre tentando melhorar. [...] Em relação aqui ao Centro de Referência e ao Centro de Reabilitação eu estou sendo bem assistida, qualquer coisa que eles olham nela, que identificam, eles já vão logo trabalhar. Mônica, 21 anos.

Aqui [na Casa de Apoio] é ótimo, eu amei aqui. Tudo ela tá fazendo, aprendi muita coisa. $\mathrm{Mel}, 20$ anos.

Eu sabia que no hospital [privado] não ia me dar estrutura pra cuidar do meu filho. Marisa, 32 anos.

O tratamento de uma criança com microcefalia necessita de uma equipe multiprofissional com processo de trabalho interdisciplinar. Nesse sentido, é essencial a criação de vínculo terapêutico entre a equipe e os pais, buscando acolher, orientar e estimular os pais durante o processo de reabilitação do filho ${ }^{31}$.

Por fim, alguns pontos avaliados negativamente, como por exemplo, tempo de espera e inexistência de alguns recursos, levaram algumas famílias a buscar alternativas para o cuidado do filho no setor privado.

Tá muito difícil consultar.[...] Eu vou pagar uma fisioterapia pra ela, porque tá difícil. Aqui [Centro de Referência] tá muito assim, tipo lerdo. Marina, 18 anos.

Lá [no interior], a fisioterapia é pelo particular, porque público eles não têm não. Paulo, 26 anos.

Esses resultados também têm sido referidos em pesquisas realizadas em outros estados, que citam que algumas mães recorreram a serviços de saúde privados devido a questões relacionadas à 
ausência de vagas, de especialistas e de estrutura física $^{15}$.

O retorno aos atendimentos não reflete, necessariamente, satisfação com os serviços encon$\operatorname{trados}^{27}$.

\section{Conclusão}

A epidemia de microcefalia, no Brasil, veio acompanhada de diversos desafios. O sistema de saúde demorou a oferecer uma resposta adequada para as crianças acometidas e suas famílias, tornando árduo o caminho percorrido entre o diagnóstico e o tratamento.

O setor profissional não estava preparado para uma pronta-resposta no início da epidemia por se tratar de uma situação nova e emergencial e, portanto, a trajetória assistencial - caminhos percorridos no setor profissional -, foi marcada pela peregrinação.

Os pais, ao enfrentarem desconhecimento e despreparo por parte de muitos profissionais e desorganização nos serviços, recorreram ao setor informal, constituído, especialmente, por famílias que viviam a mesma experiência, o que tomou grande dimensão na construção dos itinerários terapêuticos, influenciando diretamente na escolha de onde buscar tratamento.

O setor popular praticamente não foi utilizado, o que parece estar associado à gravidade da doença e à grande veiculação de informações midiáticas que sugeriam a busca pelo setor profissional.

\section{Colaboradores}

DS Bosaipo trabalhou na análise dos dados, redação e revisão do artigo. PS Oliveira trabalhou na redação do projeto, coleta e análise dos dados, redação e revisão do artigo. ZC Lamy trabalhou na idealização da pesquisa, redação do projeto, análise dos dados, redação e revisão do artigo. CMRP Gomes trabalhou na análise dos dados, redação e revisão do artigo. MRM Assis trabalhou na análise dos dados, redação e revisão do artigo. MTSSB Alves trabalhou na idealização da pesquisa, redação do projeto, redação e revisão do artigo. MRC Ribeiro trabalhou na idealização da pesquisa, redação e revisão do artigo. 


\section{Referências}

1. Brasil. Ministério da Saúde (MS). Secretaria de Atenção à Saúde. Protocolo de atenção à saúde e resposta à ocorrência de microcefalia relacionada à infecção pelo vírus zika. Ministério da Saúde, Secretaria de Atenção à Saúde. Brasília: MS; 2016.

2. Brasil. Ministério da Saúde (MS). Secretaria de Vigilância em Saúde. Secretaria de Atenção à Saúde. Orientações integradas de vigilância e atenção à saúde no âmbito da Emergência de Saúde Pública de Importância Nacional: procedimentos para o monitoramento das alteraç̃es no crescimento e desenvolvimento a partir da gestação até a primeira infância, relacionadas à infecção pelo vírus Zika e outras etiologias infeciosas dentro da capacidade operacional do SUS [recurso eletrônico] / Ministério da Saúde, Secretaria de Vigilância em Saúde, Secretaria de Atenção à Saúde. Brasília: MS; 2017.

3. No authors listed. Zika virus outbreaks in the Americas. Wkly Epidemiol Rec 2015; 90:609-610.

4. Calvet G, Aguiar RS, Melo AS, Sampaio SA, De Filippis I, Fabri A, Araujo ES, Sequeira PC, Mendonça MC, Oliveira L, Tschoeke DA. Detection and sequencing of Zika virus from amniotic fluid of fetuses with microcephaly in Brazil: a case study. The Lancet Infectious diseases 2016; 16(6):653-660.

5. Silva AC, Matos SS, Quadros MT. Economia Política do Zika: Realçando relações entre Estado e cidadão. Revista Anthropológicas 2017; 28(1):223-246.

6. Programa das Nações Unidas para o Desenvolvimento (PNUD). Uma avaliação do impacto socioeconômico do Vírus Zika na América Latina e Caribe: Brasil, Colômbia e Suriname como estudos de caso 2017. [Internet]. [acessado 2019 mar 2]. Disponível em: file:///C:/Users/Revista\%20CSC/Downloads/UNDPRBLAC-Zika-07-20-2017-Portuguese-WEB.pdf

7. Brunoni D, Blascovi-Assis SM, Osório AA, Seabra AG Amato CA, Teixeira MC, Rocha MM, Carreiro LR. Microcefalia e outras manifestações relacionadas ao vírus Zika: impacto nas crianças, nas famílias e nas equipes de saúde. Cien Saude Colet 2016; 21:32973302.

8. Núcleo de Tratamento e Estimulação Precoce (Nutep), Fundo das Nações Unidas para a Infância (Unicef). Atenção a crianças com síndrome congênita do zika vírus: relato da experiência de uma abordagem centrada na família. Fortaleza, 2017.

9. Schmidt C, Dell'Aglio DD, Bosa CA. Estratégias de coping de mães de portadores de autismo: lidando com dificuldades e com a emoção. Psicol Reflex Crit 2007 Jan;20(1):124-131.

10. Pinheiro R., Silva Junior A.G. A Centralidade do usuário na avaliação em saúde: outras abordagens. In: Pinheiro R, Martins PHN, organizadores. Avaliação em saúde na perspectiva do usuário: abordagem multicêntrica. Rio de Janeiro; CEPESP; 2011. p. 37- 52.

11. Alves PC. Itinerário terapêutico e os nexus de significados da doença. Polit Trab 2015; 42(1):29-43.

12. Kleinman A. Patients and healers in the context of culture. California: Regents; 1980.

13. Helman C. Cuidado e cura: os setores de atenção a saúde. In: Helman C. Cultura, Saúde e Doença. 5 ed. Porto Alegre: Artes Médicas; 2009. p. 79-112.
14. Alves PCB, Souza IM. Escolha e avaliação de tratamento para problemas de saúde: considerações sobre o itinerário terapêutico. In: Rabelo MC, Alves PCB, Souza IMA, organizadores. Experiência de doença e narrativa. Rio de Janeiro: Editora Fiocruz; 1999. p. 125-38.

15. Cerqueira MM, Alves RD, Aguiar MG. Experiências vividas por mães de crianças com deficiência intelectual nos itinerários terapêuticos. Cien Saude Colet 2016; 21:3223-3232.

16. Cabral AL, Martinez-Hemáez A, Andrade EI, Cherchiglia ML. Itinerários terapêuticos: o estado da arte da produção científica no Brasil. Cien Saude Colet 2011;16:4433-4442.

17. Silva AA, Barbieri MA, Alves MT, Carvalho CA, Batista RF, Ribeiro MR, Lamy-Filho, F, Lamy ZC, Cardoso VC, Cavalli RC, Simões VM, Bettiol H. Prevalence and Risk Factors for Microcephaly at Birth in Brazil in 2010. Pediatrics 2018;141(2):e20170589.

18. Minayo MCS. O desafio do conhecimento: pesquisa qualitativa em saúde. 13. ed. São Paulo: Hucitec. 2014

19. Bardin L. Análise de Conteúdo. 7 ed. Lisboa:70, editor. 2011.

20. Gerhardt TE. Itinerários terapêuticos em situações de pobreza: diversidade e pluralidade. Cad Saude Publica 2006; 22:2449-2463.

21. Ferreira J, Espírito Santo W. Os percursos da cura: abordagem antropológica sobre os itinerários terapêuticos dos moradores do complexo de favelas de Manguinhos, Rio de Janeiro. Physis 2012; 22:179-198.

22. Sari FL, Marcon SS. Participação da família no trabalho fisioterapêutico em crianças com paralisia cerebral. J Human Growth Dev 2008; 18(3):229-239.

23. Pinheiro DAJP, Longhi MR. Maternidade como missão! A trajetória militante de uma mãe de bebê com microcefalia em PE. Cadernos de Gênero e Diversidade 2017; 3(2):113-133.

24. Lira LC, Scott RP, Meira F. Trocas, Gênero, Assimetrias e Alinhamentos: experiência etnográfica com mães e crianças com síndrome congênita do Zika. Revista Anthropológicas 2017; 28(2):206-237.

25. Alves PC, Minayo MCS, organizadores. Saúde $e$ doença: um olhar antropológico [online]. Rio de Janeiro: Editora Fiocruz; 1994. 174 p.

26. Conselho Federal de Fisioterapia e de Terapia Ocupacional (COFFITO). Diagnóstico: Microcefalia- E agora? [cartilha] 2016. [acessado 2019 mar 2]. Disponível em: https://coffito.gov.br/nsite/wp-content/ uploads/comunicao/materialDownload/CartilhaMicrocefalia_Final.pdf

27. Favero-Nunes MA, Santos MA. Itinerário terapêutico percorrido por mães de crianças com transtorno autístico. Psicol Reflex Crit 2010; 23(2):208-221.

28. Governo do Maranhão. Governo inaugura Centro de Referência em Neurodesenvolvimento, Assistência e Reabilitação de Crianças (Ninar) [Internet]; 2016 mar 14. [acessado 2019 mar 2]. Disponível em: https:// www.ma.gov.br/governo-inaugura-centro-de-referencia-em-neurodesenvolvimento-assistencia-e-reabilitacao-de-criancas-ninar/ 
29. Pinho PA, Pereira PP. Itinerários terapêuticos: trajetórias entrecruzadas na busca por cuidados. Interface(Botucatu) 2012; 16(41):435-450.

30. Brasil. Lei no. 13.146, de 6 de julho de 2015. Institui a Lei Brasileira de Inclusão da Pessoa com Deficiência (Estatuto da Pessoa com Deficiência). Diário Oficial da União 2015; 7 jul.

31. Brasil. Ministério da Saúde (MS). Diretrizes de estimulação precoce: Crianças de zero a 3 anos com Atraso no Desenvolvimento Neuropsicomotor Decorrente de Microcefalia. Brasília: MS; 2016.

Artigo apresentado em 27/03/2019

Aprovado em 18/08/2019

Versão final apresentada em 20/08/2019

Editores-chefes: Romeu Gomes, Antônio Augusto Moura da Silva 